\title{
Research Paper: Larger Volume and Different Activation of the Brain in Response to Threat in Military Officers
}

\author{
Seyed Amir Hossein Batouli ${ }^{1}$ (i), Valiallah Saba ${ }^{t^{*}}$ (1)
}

1. Department of Radiology, Faculty of Paramedicine, AJA University of Medical Sciences, Tehran, Iran

\begin{tabular}{|c|c|}
\hline 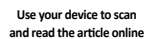 & \\
\hline 口pctin & Citation: Batouli, S. A. H., \& Saba, V. (2020). Larger Volume and Different Activation of the Brain in Response to Threat in \\
\hline 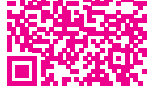 & doijhttp://dx.doi.org/10.32598/bcn.11.5.352.4 \\
\hline
\end{tabular}

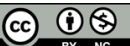

Article info:

Received: 13 Jul 2019

First Revision: 05 Aug 2019

Accepted: 15 Jan 2020

Available Online: 01 Sep 2020

Keywords:

Brain, Cognition, Military personnel, Magnetic

Resonance Imaging (MRI)

\section{A B S T RA C T}

Introduction: Military missions involve stressful and life-threatening situations; however, soldiers should have a healthy cognition on the battlefield despite their high-stress levels. This is an ability that should be gained during prior military training. Successful and influential training is suggested to be associated with structural and functional improvements of the brain

Methods: This study investigated the pattern of brain activation while observing videos relevant to life-threatening situations, in addition to brain structure. Accordingly, the obtained data were compared between 20 military members and 26 healthy controls. The study participants were all male, aged between 19 to 24 years, right-handed, studying BSc, and from the same socioeconomic status.

Results: The obtained data presented a larger volume in a total number of 1103 voxels of the brain (in 5 brain areas) in the military group. Furthermore, the military group suggested higher brain activation in the visual processing areas of the brain when observing real combat videos; however, this increment was mostly in the areas associated with motor processing and executive functions in the controls.

Conclusion: This study indicated that military training is associated with positive structural changes in the brain. Besides, it provided a different brain activation in response to stressful situations. These findings highlighted the importance of qualified military training.

\section{* Corresponding Author:}

Valiallah Saba, PhD.

Address: Department of Radiology, Faculty of Paramedicine, AJA University of Medical Sciences, Tehran, Iran.

Tel: +98 (21) 43822449

E-mail: vsaba@aut.ac.ir 


\section{Highlights}

- Military training is positively associated with brain structure alternations.

- Military training is associated with brain functionality.

- Military officers present a different brain activation in response to the threat.

\section{Plain Language Summary}

The army of a country is protecting the land, residents, property, and independence of that country. The condition of a battlefield is full of stress and life-threatening situations. Well, if an army member loses his attention and concentration during the battle, he may easily lose his life. In addition, that group of soldiers may have a lower chance to complete their mission. As a result, it is very important to know if an army member is ready for deployment and will be focused on his duties during the battle. In this study, we compared a group of young under-training army members, who had not been sent to any deployment, with a group of healthy controls. We aimed to understand if the military training in the army group was correlated with the structure and function of the brain; in other words, we expected that all those trainings suggest some associations with a healthier and more efficient brain in the army members. We observed larger volumes in some areas of the brain in the army group, i.e. expected, due to receiving high biopsychological trainings. Besides, the army group had less brain activation when observing real-combat, stressful movies. This finding reveals that they had a better regulation of their emotions against life-threatening situations. This study highlighted that the military training of our army members is efficient enough, to prepare them for deployment.

\section{Introduction}

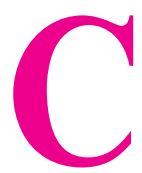

ognitive failure is prevalent in individuals under stress, which may disappear when the stress decreases (van Wingen et al., 2012); however, severe stress, like those experienced in a military mission, can longer and more severely lead to cognitive impairments. Accordingly, it influences the performance, cognitive behavior, and occupational functioning of the individuals ("Self-reported illness and health status among gulf war veterans: A population-based study", 1997). Stress is referred to as a state of threatened homeostasis in an organism, due to internal or external effects (Chrousos, 2009). The physiological response towards it would be the activation of the sympathetic nervous system and the Hypothalamic-Pituitary-Adrenal (HPA) axis (Steinbeis, Engert, Linz, \& Singer, 2015a), as well as enhanced cortisol level (Hellhammer, Wüst, \& Kudielka, 2009). This physiological response and the corresponding rises in arousal, vigilance, aggression, and attention, enable a behavioral response, called "fight-or-flight" (Steinbeis, Engert, Linz, \& Singer, 2015b).

Stress presents profound effects on human cognition (van Wingen et al., 2012); this includes not only making decisions and planning actions (Lerner \& Keltner, 2001), but also the memory and perception of sensory informa- tion (Phelps, 2004). Adverse influences of stress are also illustrated on the lack of time and place orientation (Ćosić et al., 2012), emotionality (Eiland \& Romeo, 2013), the structure of amygdalar neurons (McEwen, Nasca, \& Gray, 2015), enhanced anxiety-like behaviors (Padival, Blume, Vantrease, \& Rosenkranz, 2015), the atrophy of hippocampal cells (McEwen et al., 2015), and the executive functions (van Wingen et al., 2012). As a military example, the combat stress in the US army soldiers in Afghanistan suggested reduced midbrain activity and integrity, in association with compromised sustained attention, as well as reduced functional connectivity between the midbrain and prefrontal cortex (van Wingen et al., 2012).

Therefore, it is essential to empowering the soldiers to maintain their proper cognition and performance on the battlefield. Such measures enable them to protect themselves and complete their mission. One method to achieve this goal is through persistent military training and education. It has been suggested that military training does enable professional soldiers (even unconsciously) to control their brain activity and not being affected by threats (Ćosić et al., 2012). This ability is much weaker or unavailable in the general population. A mindfulness-based series of training also positively impacted the brain-behavior relationship in soldiers. Some examples included enhanced stress recovery, decreased plasma neuropeptide Y concentration, and attenuated 
brain activations in the insula and anterior cingulate. Emotion regulation assists individuals to tailor their emotional responses in a dynamic environment (Raio \& Phelps, 2015); however, stress exposure exerts detrimental effects on this ability among them. Mission success depends on the soldiers' ability to manage and leverage their emotions (Raio \& Phelps, 2015). Subsequently, it is vital for the soldiers to practice and gain the required skills to cognitively manage their emotions as a driving force of attention, motivation, and learning (Oden, Lohani, McCoy, Crutchfield, \& Rivers, 2015).

In addition to mental training, Physical Activity (PA) could positively influence the brain's cognitive abilities (Ang, Gomez-Pinilla, \& Gomez-Pinilla, 2007); this impact is to the extent that PA is described as the most efficient manner to have a healthy mind (van Praag, 2009). For example, aerobic exercise is observed to improve the efficiency of attentional (Kramer et al., 1999), executivecontrol (Colcombe \& Kramer, 2003), and learning (Perini, Bortoletto, Capogrosso, Fertonani, \& Miniussi, 2016) processes; a higher fitness level was reported to be associated with less cognitive decline in the elderly (Barnes, Yaffe, Satariano, \& Tager, 2003); with enhanced cognition, as well as improved learning and memory (Cotman \& Berchtold, 2002), attention, reaction time, and language (Snowden et al., 2011; Batouli \& Sisakhti, 2019), and with visuospatial, and other neurocognitive functions (Braskie et al., 2014). Additionally, resistance training improved associative memory performance and visual processing strategy (Liu-Ambrose, Nagamatsu, Voss, Khan, \& Handy, 2012). Besides, coordination training was associated with improved cognition (Niemann, Godde, \& Voelcker-Rehage, 2016). Exercise also reduces the incidence of stress-related disorders (Herrera et al., 2016), such as depression, post-traumatic stress disorder, and anxiety (Asmundson et al., 2013).

PA is positively correlated with the brain structure as well. A review study demonstrated that $>80 \%$ of the brain's gray matter is related to PA(Batouli \& Saba, 2017). The PAs included aerobic exercise, endurance, strength and balance training, weight press and stretching, as well as sports such as biking, running, martial arts, ball sports, golfing, and diving. That study indicated the substantial association of PA with the brain structure. Moreover, the relevant findings emphasized implementing PA in the programs related to improving mental abilities, including military training.

As a result, it is essential to evaluate the association between the biopsychological training of military officers and the alterations of their brain structure and function.
For this aim, this study acquired two groups of participants, consisting of military officers and controls. Both study groups were matched in terms of age, educational level, and socioeconomic status. We compared their brain structure, as well as their brain activations pattern while observing stressful movies of real combat. The current research findings could help evaluate the efficacy of our military training to prepare soldiers for deployment. Accordingly, we could save their lives and help them to complete their mission.

\section{Materials and Methods}

This study was performed per the Ethics Statement of Iran University of Medical Sciences (ethics approval code: IR.IUMS.REC.1395.899). All study participants declared their assent during the initial interview after being informed about the general purposes of the study. Accordingly, they provided signed informed consent forms on the test day. Forty-six right-handed male subjects were included in this study. Of them, 26 were healthy controls (Mean \pm SD age: $20.5 \pm 1.02$ years; age range: $19-22$ years), who were BSc students of Medicine, Nursing, or Radiology. The test group included 20 young military officers (Mean \pm SD age: $22.8 \pm 0.8$ years; age range: 20 - 24 years), who were also BSc students at an Iranian military educational institution. Besides, they had successfully passed the basic educational courses of the Iranian army, including heavy physical, martial, and military training, as well as the theoretical military educations. The two groups were selected from the same socioeconomic status; however, the military group members were older; therefore, all estimations were corrected for age.

The control group was not sedentary; however, heavy training and a few hours of physical exercise was a daily program of the military officers (for around 3 years). Thus, the amount of time and effort that the military group devotes to PA was higher than that of the controls. As evidence, the Mean \pm SD Body Mass Index (BMI) scores of the military and control groups were $21.4 \pm 1.89$ (17.7$24.8)$ and $23.1 \pm 3.22$ (17.5-30.1), respectively. The BMI measures of both research groups were in the healthy range; however, the lower BMI in the military group was statistically significant (Paired Samples t-test, $\mathrm{P}=0.047$ ).

The biopsychological health of the study participants was tested by a physician at the imaging center using our developed questionnaire, i.e. based on the inclusion/ exclusion criteria of the International Consortium for Brain Mapping (ICBM) (Mazziotta et al., 2009). The study participants were excluded due to any current or past chronic or acute neurological or internal conditions, 
medicine consumption, undergoing surgery, experiencing trauma; being overweight ( $>100 \mathrm{~kg}$ ); having a serious family history of any diseases; smoking or drug/ alcohol abuse; being claustrophobic, or having implants or any other metal objects in the body.

To assess the underlying emotional state of the participants, the Positive and Negative Affect Schedule (PANAS) test (Tran, 2013) was performed before conducting the Magnetic Resonance Imaging (MRI). As a result, the PANAS mean \pm SD scores (based on a 50 -point scale) of the military group was "positive $=38.1 \pm 4.3$ "; and "negative $=18.5 \pm 5.5$ "; for the control group, the same was "positive= 35.2 \pm 5.5 ", and "negative $=17.6 \pm 5.9$ ". The two groups did not differ in their negative or positive PANAS measures $(\mathrm{P}>0.05)$.

The functional MRI (fMRI) paradigm was designed to simulate a stressful and life-threatening situation for the study participants. For this aim, 5 conditions were randomly set up in a block-design paradigm using short web-downloaded video clips. The conditions were as follows: I) videos relevant to a European football league (football); II) short videos of real combat footage, without scenes relevant to murder, violence, or brutality (war-1); III) real footage of combat, with scenes relevant to murder and violence, but without brutality (war-2); IV) videos of combat, with murder, violence, and brutality (war-3); and V) the rest condition, which included a black cross on a white background (rest). Providing three types of war conditions was to assure that approximately all kinds of real-combat situations were presented to the research participants. The football videos were presented as neutral stimulations. The sample screenshots of the videos are provided in Figure 1.

The paradigm lasted 11:55 minutes. It comprised 6 rest conditions ( $24 \mathrm{~s}$ each), 3 football conditions ( $30 \mathrm{~s}$ each), 3 videos of war- 1 condition (30-50s each), 2 videos of war- 2 condition ( 30 s each), and 5 videos of war- 3 condition (34-60s each). The conditions were initially randomly distributed; then, the same paradigm was presented to all study participants. The videos and their sounds were presented to the research participants during the MRI scan using a goggle $(800 \times 600$-pixel resolution in a 0.25 square area and refresh rate of up to $85 \mathrm{~Hz}$ ) and an earphone $(30 \mathrm{~dB}$ noise-attenuating headset with $40 \mathrm{~Hz}$ to $40 \mathrm{kHz}$ frequency response), i.e. appropriate to up to 4.7T magnetic fields (VisuaStim, The Pennsylvania State University, USA).

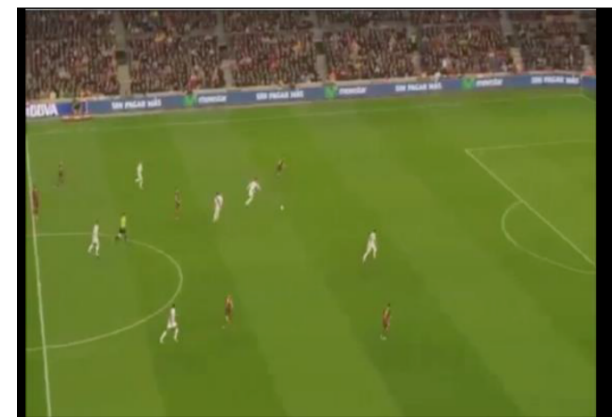

Football

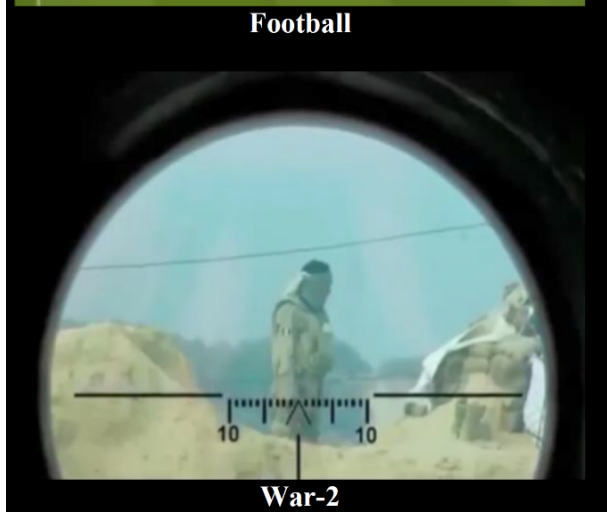

War-2
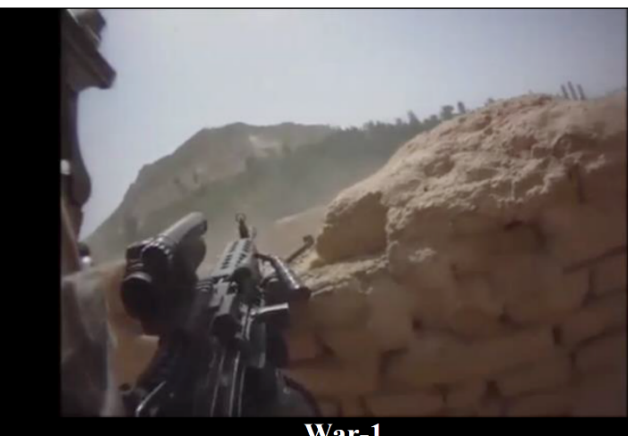

War-1

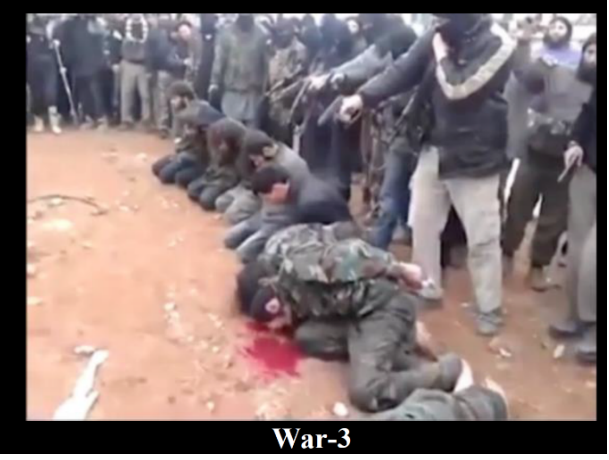

NEUR $\$$ SCIENCE

Figure 1. Sample screenshots of the presented videos

Sample screenshots of the videos being presented to the research participants during the fMRI scanning per three conditions; War-1: Real combat footage, without scenes relevant to murder, violence, or brutality; War-2: Real footage of combat with scenes relevant to murder and violence, but without brutality; War-3: Real videos of combat, including murder, violence, and brutality. Football: Videos relevant to a football game, presented as neutral stimulations. 
A checklist was followed by the examiner before each MRI scan to confirm the consent of the study subject and recognizing the study purposes. Additionally, no consumption of any antineuropathic medication, no consumption of any doping food (e.g. coffee, alcohol), or medicine on the exam day was checked. Moreover, the performance of clinical checks by the physician, setting lenses for better visualization of the goggle (if required), as well as goggle cleanness, training the participant for tasks during the scanning, requesting the participant to imaging being in the situation presented to him in the videos, and setting the headset volume on a comfortable level were observed.

The brain MRI was performed by a Siemens 3 Tesla MRI scanner (Prisma; Siemens Healthcare $\mathrm{GmbH}$, Federal Republic of Germany; Production: 2016) with a 64-channel head coil, at the National Brain Mapping Lab, Tehran City, Iran (www.nbml.ir). Functional T2×weighted images were collected using Blood Oxygen Level Dependent (BOLD) contrast, with $40 \mathrm{mT} / \mathrm{m}$ gradients, and by the coverage of the whole head. The protocol included a single-shot, spin-echo, Echoplanar Imaging $(\mathrm{EPI})$ sequence $(\mathrm{TR}=3000 \mathrm{~ms}, \mathrm{TE}=30 \mathrm{~ms}$, flip angle $=90^{\circ}, \mathrm{FOV}=192 \mathrm{~mm}^{2}$, matrix size $=64 \times 64, \&$ slice $\mathrm{gap}=0 \mathrm{~mm}$ ), and was used to acquire 40 slices with isotropic resolution $\left(3 \times 3 \times 3 \mathrm{~mm}^{3}\right)$. A Three-Dimensional (3D) T1-weighted anatomical scan was acquired prior to the EPI scan, using a gradient echo pulse sequence $(\mathrm{TR}=$ $1800 \mathrm{~ms}, \mathrm{TE}=3.44 \mathrm{~ms}, \mathrm{TI}=1100 \mathrm{~ms}$, flip angle $=7^{\circ}$, voxel size $=1 \times 1 \times 1 \mathrm{~mm}^{3}, \mathrm{FOV}=256 \times 256 \mathrm{~mm}^{2}$, matrix size $=$ $256 \times 256$, slice thickness $=1 \mathrm{~mm}, \&$ slice gap $=0 \mathrm{~mm}$ ). All obtained data were anonymized before processing.

Details of our volumetric analysis methods were previously published (Batouli, Sachdev, et al., 2014; Keihani et al., 2017). As a summary, initially, the quality of the T1-weighted scans was visually checked for a correct orientation and matrix size, for a proper signal to noise ratio, and no artifacts, using the Display toolbox, SPM12 (Welcome Department of Imaging Neuroscience: http:// www.fil.ion.ucl.ac.uk/spm), in MATLAB (version 9.0). No scan was excluded in this step. Next, VBM analysis was performed as follows. The scans were segmented into GM, WM, and CSF employing the segmentation toolbox, which created the native space plus Diffeomorphic Anatomical Registration Through Exponentiated Lie Algebra (DARTEL) imported outputs (Ashburner, 2010). This process was conducted using the default settings of the "Run DARTEL: create template" toolbox; the accuracy of inter-subject alignment was improved by iteratively averaging the DARTEL-imported data of the GM and WM tissue types to generate population- specific templates. Furthermore, after generating the templates, all the GM and WM images were normalized to the Montreal Neurological Institute (MNI) standard space, using the Normalize to MNI space toolbox. Eventually, all images were smoothed with a Gaussian kernel (10mm FWHM) before running the statistical analyses.

The total cerebral volume of all study subjects was estimated by adding the probability estimates of the GM and WM maps then multiplying the resulted values to $3.375 \mathrm{~mm}^{3}$ (the volume of one voxel). The total volumes were required for statistical inferences. Using global calculation, the study groups were compared in a voxel-wise manner, using Independent Samples t-test at the significance level of $\mathrm{P}<0.001$ (corrected for voxellevel multiple comparisons using the family-wise error correction). The implicit masking of the final images was eventually performed with a relative threshold. This measure helped to eliminate any effect of edge differences between the research groups.

The fMRI data analysis detailed was also previously published (Batouli, Hasani, Gheisari, Behzad, \& Oghabian, 2016). This analysis was performed using the fMRI Expert Analysis Tool (FEAT), part of FMRIB's Software Library (FSL, http://www.fmrib.ox.ac.uk/fsl) (version 5.0.9). Pre-processing steps included motion correction using FSL, Motion Correction from FMRIB's Linear Image Registration Tool (MCFLIRT); skullstripping for the removal of non-brain tissue using Brain Extraction Tool, FSL (BET); slice-timing correction by Fourier-space time-series phase-shifting; the normalization of the functional images to the standard Montreal Neurological Institute (MNI) brain atlas in two steps, as follows: I) the co-registration of each individual's functional images to his high-resolution T1-weighted scan, using FMRIB's Linear Image Registration (FLIRT) and 7 Degrees of Freedom (DOF); II) the linear registration of the structural T1 images to the MNI space, with 12 DOF; using a Gaussian kernel of FWHM= $6.0 \mathrm{~mm}$ for spatial smoothing; the multiplicative mean intensity normalization of the volume at each time point; and high pass temporal filtering (Gaussian-weighted least-squares straight-line fitting, with sigma $=60.0 \mathrm{~s}$ ).

The parametric statistical analysis was based on a General Linear Model (GLM) and performed using FEAT (version 6.0.0), FSL. The FMRIB Improved Linear Model (FILM) pre-whitening was implemented for the statistical analysis of the fMRI time-series. This procedure helped to make the statistical approaches valid and maximally efficient, which devoted a z-score to the corresponding BOLD signal. Three regressors were defined 
in the analysis, corresponding to the three war conditions. The individual GLM analyses were performed by creating a boxcar function of tasks (different conditions) against rest; being convolved with a canonical hemodynamic response function and its temporal derivatives. As explained above, we also registered the estimated function map to the corresponding structural image and ultimately the MNI space. For each subject, three contrast images were produced.

The group-level analysis was conducted applying FMRIB's Local Analysis of Mixed Effects (FLAME) to estimate within-group averages. Besides, it was employed for between-group comparisons using the three contrast images of the study subjects. Cluster thresholding was performed to only reveal the significantly-active clusters.
The initial criteria for identifying active clusters was a voxel-level probability threshold of $\mathrm{Z}>2.3$; a false discovery rate (PFDR $<0.05$ ) was also used to correct multiple comparisons; however, for a higher assurance of the findings, we finally selected a more stringent $\mathrm{P}<0.005$, which corresponded to a $Z>2.6$. The effect size of the comparisons between the two groups, based on Cohen's $\mathrm{d}$ formula (Kim, 2016) was estimated to be $\mathrm{d}=0.38$, i.e. regarded as a "medium" effect size (Kim, 2015). Furthermore, it is interpreted as $65 \%$ of the military group being above the mean value of the controls.

\section{Results}

The average brain activations of study groups in the three conditions were initially estimated. The details of these

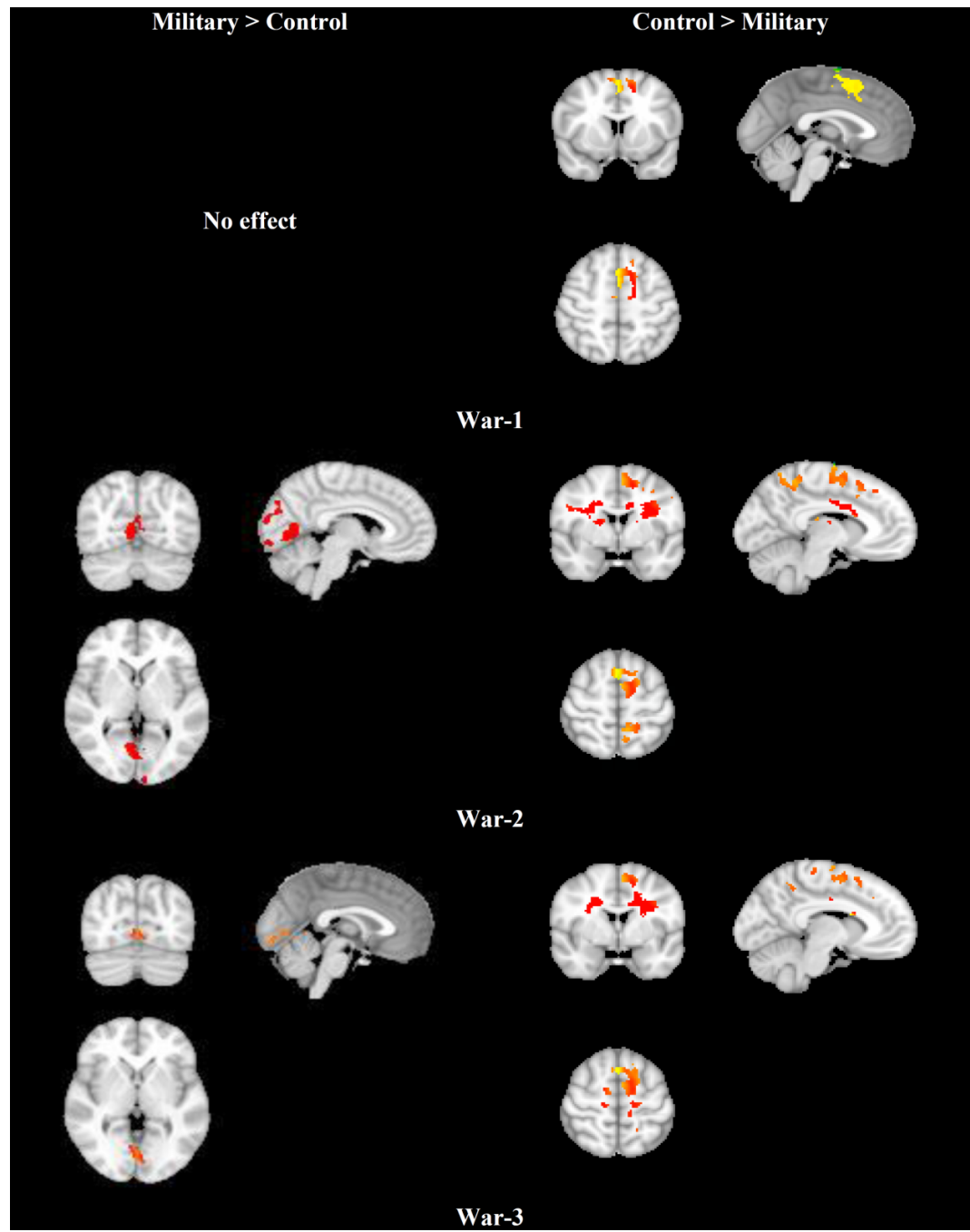

Figure 2. The fMRI data analysis results

The results of the contrasts between the fMRI maps of the military and control groups; the brain maps in the three war conditions were contrasted between the study groups to test any differences between their brain activations while observing the relevant videos; the military group presented higher activations in the occipital lobe of the brain, and this was mostly detected in the frontal areas for the control group. 
Table 1. Active brain areas during the three conditions

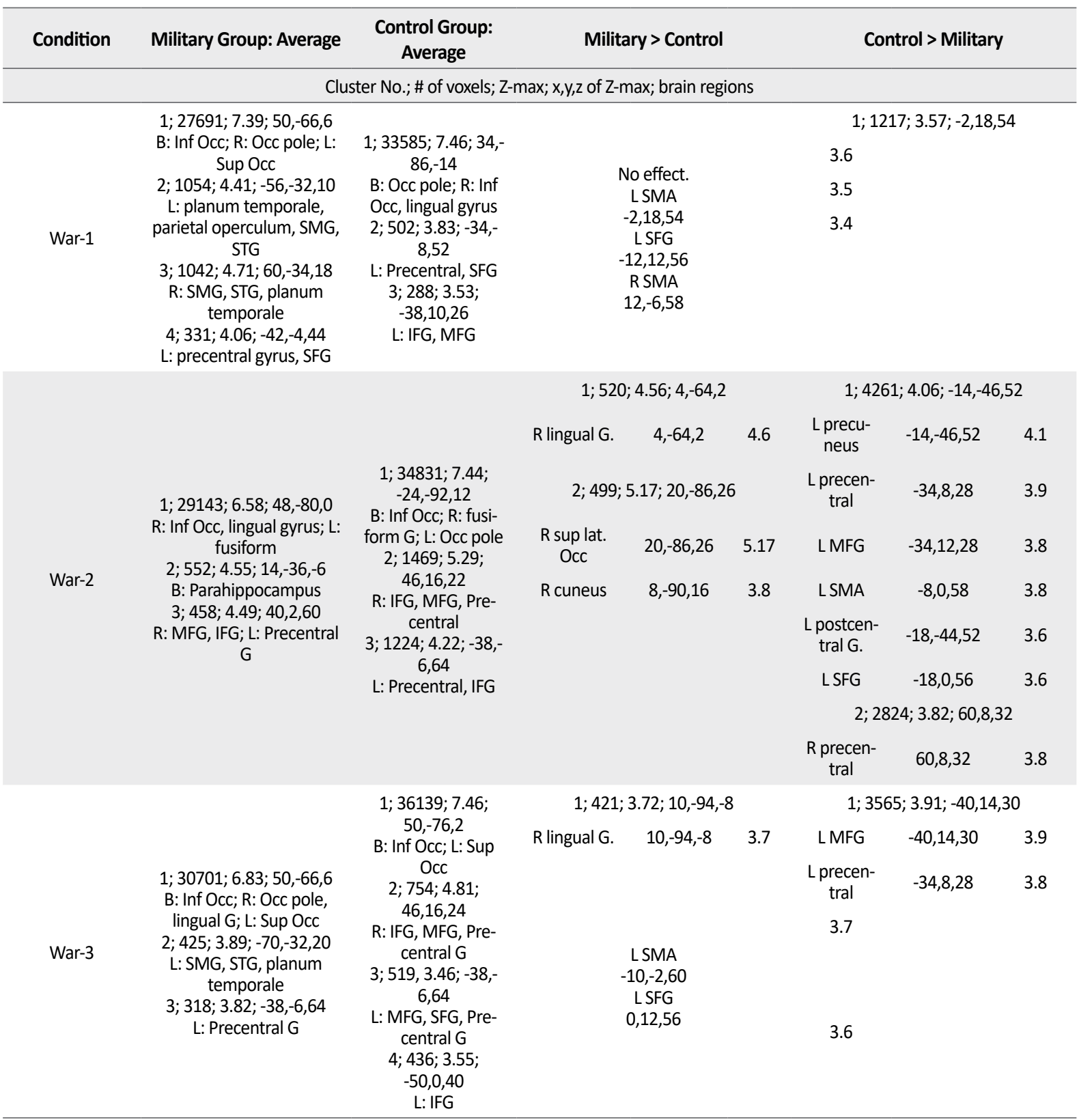

NEUR SCIENCE

Average brain activations of the military and control groups, as well as the contrasts between them, in addition to the number of voxels, z-value, coordinates, and included brain regions of each cluster; Maximum z-value and coordinates of the brain areas which showed different activations between the two groups are also provided; B: bilateral; R: right; L: left

activations, including size, coordinates, and the maximum $\mathrm{Z}$-value of the activation clusters are provided in Table 1.

Table 1 presents the average brain activations of the military and control groups, as well as the contrasts between them, in addition to the number of voxels, Zvalue, coordinates, and included brain regions of each cluster; maximum Z-value, and the coordinates of the brain areas, reflecting different activations between the research groups.

The first type of movies relevant to war activated bilateral Inf. Occ, planum temporale, Superior Temporal Gyrus (STG), and Supramarginal Gyrus (SMG) in the military group. These alternations were in addition to the right Occ pole, and the left Superior Occipital Gyrus (SOC), parietal operculum, Superior Frontal Gyrus 

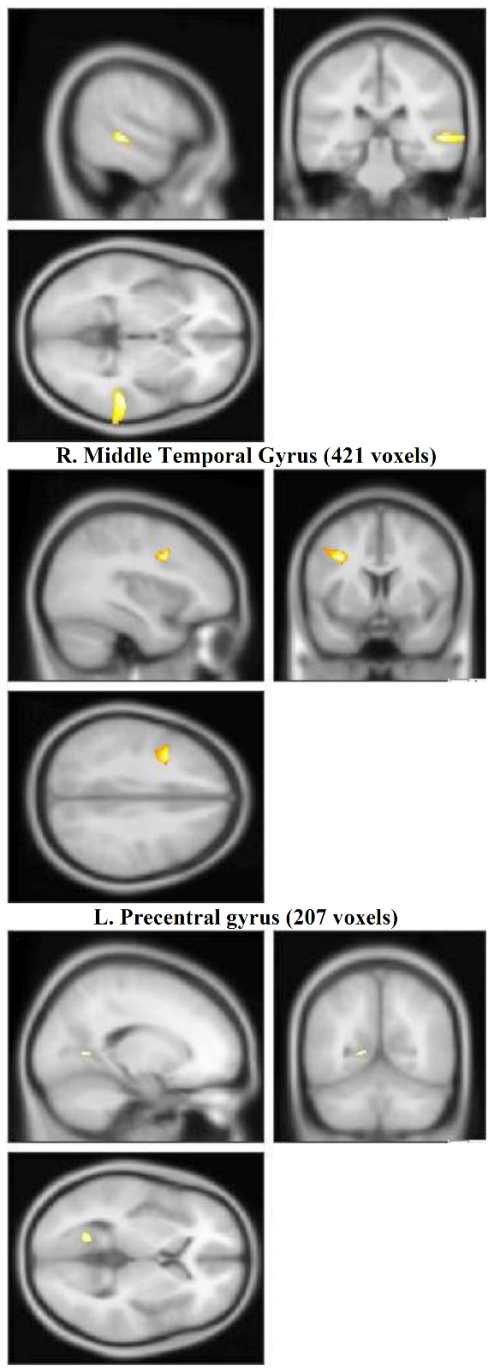

L. Posterior Cingulate (56 voxels)
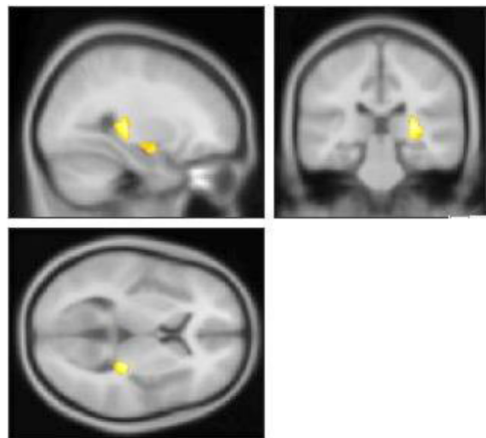

R. Hippocampus ( 288 voxels)
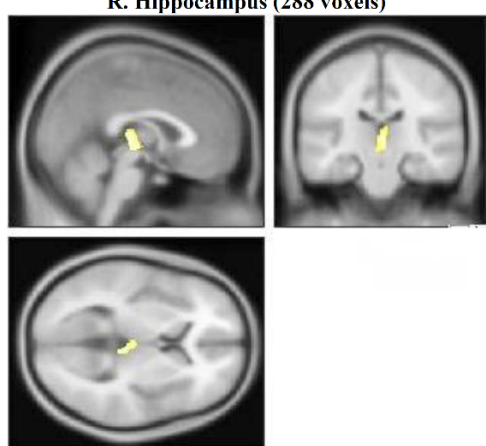

R. Thalamus (131 voxels)

Figure 3. The volumetric analysis data

NEUR SCIENCE

The five areas of the brain which illustrated a larger volume in the military group, compared to controls, using a VBM analysis method; the areas included the right middle temporal gyrus, right hippocampus, left precentral gyrus, right thalamus, and left posterior cingulate. The colored pixels represent the brain regions overlaid on a standard (in the MNI space) T1-weighted scan of the brain.

(SFG), and precentral gyrus. The control group also presented brain activations in this condition in bilateral Occ pole, right Inf. Occ, lingual gyrus, left precentral, SFG, IFG, and MFG.

War-2 videos activated bilateral parahippocampus, right Inf. Occ, lingual gyrus, MFG, IFG, left fusiform, and precentral gyri in the military group. The brain activations of this condition in the control group included bilateral Inf. Occ, precentral, IFG, right fusiform, MFG, and left Occ pole.

The War-3 videos activated bilateral Inf Occ, right Occ pole, lingual gyrus, left SOG, SMG, STG, planum temporal, and precentral gyri in the military group. Further- more, the brain activations of the control group relevant to this condition were bilateral Inf Occ, IFG, MFG, precentral gyri, as well as the left SOG and SFG.

The brain activations of the study groups in the three conditions were contrasted during the analysis (military $>$ control \& control $>$ military); the relevant maps are provided in Figure 2. In the war-1 condition, the military group presented no higher brain activations, compared to the controls. However, bilateral SMA and left SFG were more active in the controls in this condition. During the war- 2 condition, the right lingual gyrus, superior lateral Occ, and cuneus were more active in the military group, compared to the controls. Besides, the bilateral precentral gyrus as well as the left precuneus, 
MFG, SMA, SFG, and postcentral gyrus were more active in the controls, compared to the military group. Finally, the right lingual gyrus was more active in the military group during the war-3 condition, whereas left MFG, SMA, SFG, and precentral gyri demonstrated higher activations in the controls.

The VBM analysis data revealed differences between the brain structures of the research groups, as illustrated in Figure 3. Accordingly, the military group presented larger volumes in 1103 voxels in 5 brain areas, including right middle temporal gyrus (421 voxels; x,y,z: 57,-31,2), right hippocampus (288 voxels; x,y,z: 28,-28,6), left precentral gyrus (207 voxels; $x, y, z:-36,6,36)$, right thalamus (131 voxels; x,y,z: 2,-22,4), and left posterior cingulate (56 voxels; x,y,z: $-17,-59,3)$. These results were obtained at a $\mathrm{P}<0.001,43$ DOFs, and $\mathrm{t}=3.29$.

\section{Discussion}

We compared structural and functional MRI scans of two groups of participants, including 20 professional military members and 26 healthy controls. Furthermore, the study groups were of the same age, educational level, socioeconomic status, and emotional state. Our results reported 1103 voxels in 5 brain areas to have a larger volume in the military group. In addition, the fMRI maps indicated differences between the brain activations of the two groups during observing movies relevant to stressful combat situations.

The patterns of brain activation varied between the study groups during the war conditions. Considering the three war conditions together, the military group suggested higher activations in the lingual and superior lateral occipital gyri, as well as the cuneus, all in the occipital lobe. In general, this brain lobe is involved in visual perception ( $\mathrm{Li}$ et al., 2015); perceiving the external stimuli; and transferring data to the brain regions related to emotion processing and responding (Adolphs, 2001). Additionally, these areas are involved in feature-extraction, shape recognition, and the integration of visual, phonological, and semantic information (Merriam \& Colby, 2005); visuomotor transformations necessary to orient in space, like juggling (Goodale \& Milner, 1992); processing an object's position (Gerber et al., 2014), or the speed of a moving stimulus (Rodman \& Albright, 1987). There are specific functional roles of the brain areas, i.e. more active in the military group, such as the occipitotemporal areas involved in feature extraction, shape recognition, as well as the integration of visual, semantic, and phonological information (Merriam \& Colby, 2005); or being active in tasks that stimulate visuospatial processing (Niemann, Godde, Staudinger, \& Voelcker-Rehage, 2014).
These data suggest that the military group allocated more resources for perceiving and processing the visual information, compared to the controls, i.e. consistent with previous research (Li et al., 2015).

On the other hand, the brain areas more active in the controls in this condition were Supplementary Motor Area (SMA), Primary Motor Cortex (PMC), superior and middle frontal gyri, and primary somatosensory, as well as the premotor cortices. These areas impact motor planning and execution (Doyon \& Benali, 2005). They also affect working memory, executive functions, and decision making (Jacini et al., 2009). The activation level of these areas also altered during stressful conditions (Ćosić et al., 2012). The suggestions for this pattern of activation in the controls could address their higher susceptibility towards stressful events, their lower inhibition capacity, and less experience of stressful situations. The specific roles of the active areas support this suggestion. For example, increased activation of precentral, postcentral, and middle frontal gyri is associated with negative emotional imaging (Li et al., 2015); the SMA is strongly associated with the primary motor, as well as the midcingulate cortices (Schlaffke et al., 2014). Therefore, it is involved in motor control (Dayan \& Cohen, 2011) and the planning of complex and coordinated movements (Chouinard \& Paus, 2006). Furthermore, this area influences coordinating the temporal sequences of actions, bimanual coordination, postural stability, and internally generated movements (Goble et al., 2010); the PMC affects response selection based on arbitrary cues, and the control of arms (Schlaffke et al., 2014), and sequential movements (Schubotz \& von Cramon, 2001). Besides, the ventral PMC is associated with mental imagination and movement observation (Caspers, Zilles, Laird, \& Eickhoff, 2010). The right PMC also reflects spatial processing, whereas the left is mainly involved in later phases of motor learning (Ghilardi et al., 2000).

We observed a lower functionality of the brain areas corresponding to motor actions and executive functions in the military group. One explanation could be their higher capacity for emotion regulation and response inhibition. This quality enabled them to modulate their brain activity. A study revealed that individuals who performed well under severe stress presented a more efficient functioning of the insula, i.e. a lower activation (Paulus et al., 2010). Another study indicated that a military group receiving a mindfulness training presented attenuated activations in the insula and ACC. These alternations occurred when observing emotional faces, the areas being involved in cognitive control, emotion regulation, reward monitoring, and interoception (Lutz 
et al., 2014). The extent of brain activation reduction in these areas was also associated with the level of resilience improvement after receiving mindfulness training. Reduced activation of ACC during a flanker task was also reported, being interpreted as a more efficient information processing in this region (Voelcker-Rehage, Godde, \& Staudinger, 2011). Furthermore, meditators reflected lower posterior insula activation during attentional control, compared to non-meditators (Brefczynski-Lewis, Lutz, Schaefer, Levinson, \& Davidson, 2007). One other explanation for lower brain activation in the military group could be the forebrain-to-midbrain switch when the threat is proximal, and the role of vmPFC in fear inhibition (Mobbs et al., 2009). The default network of the brain becomes deactivated when a critical external cue is presented (Greicius, Krasnow, Reiss, \& Menon, 2003). Besides, this deactivation, like the one in the PFC, is associated with devoting external attention to the environment (Buckner, Andrews-Hanna, \& Schacter, 2008) to more specifically react to a potential threat. These findings suggest that specific types of mental training are correlated with the decreased requirement of cognitive resources to perform a task ( $\mathrm{Ph}$ et al., 2015); they also help in more efficient processing of stress cues.

The biopsychological training also assisted soldiers with their recovery from stress after the deployment $(\mathrm{Ph}$ et al., 2015). Furthermore, practicing emotion regulation methods helps individuals to replace ineffective decision-making with a productive response to stressful and challenging conditions (Oden et al., 2015). This result is important, as the military relies on preparing warfighters for highly-complex situations.

Contrarily, we observed a higher activation in the military group during the war condition in the brain areas relevant to visual processing. There is substantial evidence that coordination training leads to increased activation of the visuospatial network (Voelcker-Rehage et al., 2011). In general, physical training could provide functional changes in specific brain areas, leading to a general improvement in human cognition (Duchesne et al., 2016). Scholars documented alternations in the electrical oscillations of the brain due to physical training (Ermutlu, Yücesir, Eskikurt, Temel, \& İşoğlu-Alkaç, 2015). Twelve months of resistance training demonstrated functional changes in two brain areas associated with response inhibition, middle temporal gyrus, and anterior insula extending into lateral OFC (Liu-Ambrose et al., 2012); even one week of training-induced learning-related changes in the functional connectivity of brain areas was reported (Della-Maggiore \& McIntosh, 2005). One suggested mechanism for the association between PA and the brain func- tion alteration is that chronic exposure to cardiovascular and resistance training is correlated with increased metabolic demands. Therefore, the need for glucose and oxygen increases in the active neurons (Ding et al., 2004). Besides, a lower BMI is associated with a healthier brain and an improved cognitive capacity (Flöel et al., 2010).

The brain volume was larger in 5 areas in the military group, compared to the controls. The human brain is elastic, i.e. its structure alters to adapt to new demands (Lövdén, Bäckman, Lindenberger, Schaefer, \& Schmiedek, 2010 ). Our previous review study suggested that $>80 \%$ of the GM of the brain was positive associated with PA (Batouli \& Saba, 2017). Moreover, all the 5 brain regions in that review study presented such association; the number of studies (among 53 studies) that reported these 5 regions to correlated with PA was 14 for the hippocampus, 9 for the middle temporal gyrus, 4 for the precentral gyrus and posterior cingulate, and 1 for the thalamus.

It is reported that those areas of the brain which present structural changes in association with PA are mainly essential for motor-related functions (Lerch et al., 2011; Mårtensson et al., 2012). For instance, the hippocampus presents increased neurogenesis and a higher cerebral blood volume induced by exercise (Pereira et al., 2007). It is also responsible for the encoding and consolidation of motor skills (Albouy et al., 2008); the middle temporal gyrus is significantly involved in motor learning and memory (Doyon \& Benali, 2005); the precentral gyrus is a primary site of the motor cortex; cingulate cortex coordinates complex motor movements concerning higher-order attentional demands (Rovio et al., 2010); PCC mediates executive functions (Hillman, Erickson, \& Kramer, 2008), and in particular, integrates multimodal sensory data for the planning and execution of complex movements (Amiez \& Petrides, 2014); thalamus relays sensory-motor signals to the cerebral cortex and is known as a subcortical motor center. Despite involvement in motor-related functions, these areas are engaged in other cognitive abilities as well. These data explain the association of PA with general cognitive improvements among individuals. For example, the hippocampus impacts navigation and spatial representation skills (Stickgold, Malia, Maguire, Roddenberry, \& O'Connor, 2000), spatial memory (Lee, Miyasato, \& Clayton, 1998), and retrieval (Brodziak, 2013); PCC is associated with navigation ability (Maguire et al., 2000), spatial memory (Friedman et al., 1998), the recognition and retrieval of previously encountered information (Liégeois et al., 2004), semantic priming (O’Hare, Dien, Waterson, \& Savage, 2008), and moral judgments (Raine \& Yang, 
2006); and precentral gyrus is involved in spatial working memory (Weinstein et al., 2012).

There are some candidate mechanisms for the activity-related structural changes of the brain. PA results in elevated blood flow and volume in the brain (Yau, GilMohapel, Christie, \& So, 2014). PA is also related to the growth of capillaries (Palmer, Willhoite, \& Gage, 2000) and the number of small blood vessels (Bullitt et al., 2009). Considering that 5\% of GM tissue is accounted for vasculature (Barbier, Lamalle, \& Décorps, 2001), any elevation of the above-mentioned factors could contribute to the increment of the neural volume. In addition, the increment of blood flow in the brain could be associated with the development of new neurons (Dishman et al., 2006; Draganski \& May, 2008; Pereira et al., 2007), i.e. interpreted as a larger GM volume or density. A few candidate mechanisms include elevated cell proliferation (Maguire et al., 2003), angiogenesis (Cotman \& Berchtold, 2002), neurogenesis (Heo et al., 2014; van Praag, Kempermann, \& Gage, 2000), synaptogenesis (Kleim et al., 2002; Kobilo et al., 2011), and myelination (Canu, Carnaud, Picquet, \& Goutebroze, 2009; Ruegg, Kakebeeke, Gabriel, \& Bennefeld, 2003). Hippocampus is among the brain regions where neurogenesis mostly occurs (Gross, 2000). One explanation could be that PA elevates the level of some proteins in the brain, such as High-Density Lipoprotein-Cholesterol (HDL-C); Insulin-Like Growth Factor 1 (IGF-1); Vascular Endothelial Growth Factor (VEGF) (Cassilhas et al., 2007); the level of Brain-Derived Neurotrophic Factor (BDNF) (Tang, Chu, Hui, Helmeste, \& Law, 2008; Voss, Vivar, Kramer, \& van Praag, 2013), and the Nerve Growth Factor (NGF) (Ang, 2007). Besides, these proteins and factors support the above-mentioned processes, such as the neural growth and survival (Cao et al., 2007), cell genesis (van Praag, 2009), and the formation of new blood vessels (Hillman et al., 2008). Finally, PA alters the concentration of brain metabolites, such as glutamate/glutamine (GLX) (Biedermann et al., 2012), NAA (Erickson et al., 2012; Gonzales et al., 2013), and lactate (Kuipers, Keizer, Vries, Rijthoven, \& Wijts, 1988). It has been documented that one explanation for BV changes could be alterations in the level of brain metabolites (Pajonk \& et al., 2010).

The explored military group was trained with the basic physical exercises of the army for approximately three years. Studies have illustrated that different types, durations, and volumes of PAs present various levels of association with the brain structure. Different types of PAs are associated with the brain structure; from aerobic exercise, endurance, and balance training, to sports, such as biking, martial arts, and ball sports, as well as to general physical activities, such as dancing, gardening, and walking (Batouli \& Saba, 2017), albeit with different levels of association. For example, a larger hippocampal volume was observed in endurance athletes, compared to martial artists (Schlaffke et al., 2014). The duration of exercise is another determining factor in this respect. The time-scale for the structural changes of the brain in association with PA is much shorter than 10 years of practicing Judo (Jacini et al., 2009) or 5 years of dancing (Niemann et al., 2016); 6 weeks of aerobic exercise (Thomas et al., 2016), 1 week of practicing a complex visuomotor rotation task (Landi, Baguear, \& Della-Maggiore, 2011), or even 4 days of practicing the signature with the non-dominant hand (Hamzei, Glauche, Schwarzwald, \& May, 2012). The PA volume is also critical, and the reports range from 6.5 hours (Wei, Zhang, Jiang, \& Luo, 2011) or 45 minutes (Sehm et al., 2014) per day, to 180 (Colcombe et al., 2006; Niemann et al., 2014) or 120 minutes (Mueller et al., 2015) per week. It is suggested that short-term and high-volume, as well as long-term and low-volume PAs, are positively associated with the brain structure (Ruscheweyh et al., 2011).

This study aimed at identifying the associations between military training and the structural and functional changes in the brain. We considered strict inclusion criteria for the study participants, and selected robust imaging and analysis methods, to obtain reliable results. We presented real combat movies to the research participants to simulate the situation for them. Subsequently, it was revealed that brain areas illustrated higher activity in response to dynamic versus static emotional stimuli (Trautmann, Fehr, \& Herrmann, 2009). Despite its strengths, this study had a few limitations. Although hurting humans is morally prohibited, on some occasions, such as warfare, killing enemy soldiers becomes justified (Molenberghs et al., 2015). Besides, the neural circuits of justified and unjustified killings may be different, i.e. not tested here. Second, the optimal approach to examine the association of PA with $\mathrm{BV}$ is comparing volumetric measures before and after a period of exercise, i.e. impossible in the present research. Additionally, although we tried to match the participants of the two groups for age, handedness, gender, educational level, socioeconomic status, and the emotional state, the possibility of inter-individual differences and their influences on our findings could not be neglected. Eventually, a PANAS test after the imaging session, to assess the behavioral responses of the participants towards the movies, could have added useful data to our findings. 


\section{Conclusion}

Our results were different with the only similar study identified. A study (Ćosić et al., 2012) presented that the military group had higher activations in the posterior parietal, posterior temporal, premotor, and prefrontal areas of the brain while watching the videos of combat, compared to the controls. The number of active ROIs, as well as the overall number of active voxels, were also higher in their military group. They interpreted their findings as the military group to have a better understanding of the conditions of the videos. We agree with their interpretation; however, this was a pilot study with only two combat servicemen versus two mission-ready soldiers. Thus, replication might be required.

Furthermore, several studies have reported negative associations of military deployments with brain health and cognitive abilities. Our military group was under training and had never experienced a real combat situation; therefore, our results on the positive associations of military training with the alteration of brain structure and function could not be in contrast with previous investigations.

Besides the applications in the military, our findings are beneficial for providing healthy aging. Brain volume declines in the elderly (Batouli et al., 2014; Raz et al., 2004; Sachdev et al., 2013), and the human brain is under the influences of both genetic and environmental factors (Sachdev et al., 2013). Accordingly, the heritability of brain volume decreases in old age, and the impact of environmental factors increases (Batouli et al., 2014; Batouli, Trollor, Wen, \& Sachdev, 2014). Thus, providing beneficial environmental factors and a healthy lifestyle for the elderly seems to be the best approach for healthy aging (Batouli et al., 2014). A study indicated that only one year of aerobic exercise was equal to adding 1 to 2 years to brain health (Erickson et al., 2010).

\section{Ethical Considerations}

\section{Compliance with ethical guidelines}

This study was approved by the Ethics Committee of Iran University of Medical Sciences (Code: IR.IUMS. REC.1395.899).

\section{Funding}

AJA University of Medical Sciences financially supported this work.
Authors' contributions

All authors equally contributed in preparing this article.

\section{Conflict of interest}

The authors declared no conflict of interest.

Acknowledgments

We thank the cooperation of the National Brain Mapping Lab (NBML) in this study.

\section{References}

Adolphs, R. (2001). The neurobiology of social cognition. Current Opinion in Neurobiology, 11(2), 231-9. [DOI:10.1016/S09594388(00)00202-6]

Albouy, G., Sterpenich, V., Balteau, E., Vandewalle, G., Desseilles, M., \& Dang-Vu, T., et al. (2008). Both the hippocampus and striatum are involved in consolidation of motor sequence memory. Neuron, 58(2), 261-72. [DOI:10.1016/j.neuron.2008.02.008] [PMID]

Amiez, C., \& Petrides, M. (2014). Neuroimaging evidence of the anatomo-functional organization of the human cingulate motor areas. Cerebral Cortex, 24(3), 563-78. [DOI:10.1093/cercor/ bhs329] [PMID]

Ang, E. T., \& Gomez-Pinilla, F. (2007). Potential therapeutic effects of exercise to the brain. Current Medicinal Chemistry, 14(24), 2564-71. [DOI:10.2174/092986707782023280] [PMID]

Ashburner, J. (2010). VBM tutorial. Retrieved from https:// www.fil.ion.ucl.ac.uk/ john/misc/VBMclass10.pdf

Asmundson, G. J. G., Fetzner, M. G., DeBoer, L. B., Powers, M B., Otto, M. W., \& Smits, J. A. J. (2013). Let's get physical: A contemporary review of the anxiolytic effects of exercise for anxiety and its disorders. Depression and Anxiety, 30(4), 362-73. [DOI:10.1002/da.22043] [PMID]

Barbier, E. L., Lamalle, L., \& Décorps, M. (2001). Methodology of brain perfusion imaging. Journal of Magnetic Resonance Imaging, 13(4), 496-520. [DOI:10.1002/jmri.1073] [PMID]

Barnes, D. E., Yaffe, K., Satariano, W. A., \& Tager, I. B. (2003). A longitudinal study of cardiorespiratory fitness and cognitive function in healthy older adults. Journal of the American Geriatrics Society, 51(4), 459-65. [DOI:10.1046/j.15325415.2003.51153.x] [PMID]

Batouli, S. A. H., Hasani, N., Gheisari, S., Behzad, E., \& Oghabian, M. A. (2016). Evaluation of the factors influencing brain language laterality in presurgical planning. Physica Medica 32(10), 1201-9. [DOI:10.1016/j.ejmp.2016.06.008] [PMID]

Batouli, S. A. H., \& Saba, V. (2017). At least eighty percent of brain grey matter is modifiable by physical activity: A review study. Behavioural Brain Research, 332(Supplement C), 204-17. [DOI:10.1016/j.bbr.2017.06.002] [PMID] 
Batouli, S. A. H., Sachdev, P. S., Wen, W., Wright, M. J., Ames, D., \& Trollor, J. N. (2014). Heritability of brain volumes in older adults: The older Australian twins study. Neurobiology of Aging, 35(4), 937.e5-18. [DOI:10.1016/j.neurobiolaging.2013.10.079] [PMID]

Batouli, S. A. H., \& Sisakhti, M (2019). Investigating A Hypothesis on The Mechanism of Long-term Memory Storage. NeuroQuantology, 17(3) . [DOI:10.14704/NQ.2019.17.3.1813] https://www.neuroquantology.com/index.php/journal/ article/view/1813/1346

Batouli, S. A. H., Trollor, J. N., Wen, W., \& Sachdev, P. S. (2014) The heritability of volumes of brain structures and its relationship to age: A review of twin and family studies. Ageing Research Reviews, 13, 1-9. [DOI:10.1016/j.arr.2013.10.003] [PMID]

Biedermann, S., Fuss, J., Zheng, L., Sartorius, A., Falfán-Melgoza, C., \& Demirakca, T., et al. (2012). In vivo voxel based morphometry: Detection of increased hippocampal volume and decreased glutamate levels in exercising mice. NeuroImage, 61(4), 1206-12. [DOI:10.1016/j.neuroimage.2012.04.010] [PMID]

Braskie, M. N., Boyle, C. P., Rajagopalan, P., Gutman, B. A., Toga, A. W., \& Raji, C. A., et al. (2014). Physical activity, inflammation, and volume of the aging brain. Neuroscience, 273, 199-209. [DOI:10.1016/j.neuroscience.2014.05.005] [PMID] [PMCID]

Brefczynski-Lewis, J. A., Lutz, A., Schaefer, H. S., Levinson, D. B., \& Davidson, R. J. (2007). Neural correlates of attentional expertise in long-term meditation practitioners. Proceedings of the National Academy of Sciences of the United States of America, 104(27), 11483-8. [DOI:10.1073/pnas.0606552104] [PMID] [PMCID]

Brodziak, A. (2013). A current model of neural circuitry active in forming mental images. Medical Science Monitor: International Medical Journal of Experimental and Clinical Research, 19, 1146-58. [DOI:10.12659/MSM.889587] [PMID] [PMCID]

Bullitt, E., Rahman, F. N., Smith, J. K., Kim, E., Zeng, D., \& Katz, L. M., et al. (2009). The effect of exercise on the cerebral vasculature of healthy aged subjects as visualized by MR angiography. American Journal of Neuroradiology, 30(10), 1857 LP-1863. [DOI:10.3174/ajnr.A1695] [PMID] [PMCID]

Canu, M. H., Carnaud, M., Picquet, F., \& Goutebroze, L. (2009). Activity-dependent regulation of myelin maintenance in the adult rat. Brain Research, 1252, 45-51. [DOI:10.1016/j.brainres.2008.10.079] [PMID]

Cao, L., Dhilla, A., Mukai, J., Blazeski, R., Lodovichi, C., \& Mason, C. A., et al. (2007). Genetic modulation of BDNF signaling affects the outcome of axonal competition in vivo. Current Biology, 17(11), 911-21. [DOI:10.1016/j.cub.2007.04.040] [PMID] [PMCID]

Caspers, S., Zilles, K., Laird, A. R., \& Eickhoff, S. B. (2010). ALE meta-analysis of action observation and imitation in the human brain. NeuroImage, 50(3), 1148-67. [DOI:10.1016/j.neuroimage.2009.12.112] [PMID] [PMCID]

Cassilhas, R. C., \& Viana, V. A. R., Grassmann, V., Santos, R. T., Santos, R. F., \& Tufik, S., et al. (2007). The impact of resistance exercise on the cognitive function of the elderly. Medicine E Science in Sports \& Exercise, 39(8), 1401-7. [DOI:10.1249/ mss.0b013e318060111f] [PMID]
Chouinard, P. A., \& Paus, T. (2006). The primary motor and premotor areas of the human cerebral cortex. The Neuroscientist, 12(2), 143-52. [DOI:10.1177/1073858405284255] [PMID]

Chrousos, G. P. (2009). Stress and disorders of the stress system. Nature Reviews Endocrinology, 5(7), 374-81. [DOI:10.1038/ nrendo.2009.106] [PMID]

Colcombe, S., Erickson, K., Scalf, P., Kim, J., Prakash, R., \& McAuley, E., et al. (2006). Aerobic exercise training increases brain volume in aging humans. The Journals of Gerontology: Series A, Biological Sciences and Medical Sciences, 61(11), 1166-70. [DOI:10.1093/gerona/61.11.1166] [PMID]

Colcombe, S., \& Kramer, A. F. (2003). Fitness effects on the cognitive function of older adults. Psychological Science, 14(2), 125-30 [DOI:10.1111/1467-9280.t01-1-01430] [PMID]

Ćosić, K., Popović, S., Fabek, I., Kovač, B., Radoš, M., \& Radoš, M., et al. (2012). fMRI neural activation patterns induced by professional military training. Translational Neuroscience, 3(1), 46-50. [DOI:10.2478/s13380-012-0012-2]

Cotman, C. W., \& Berchtold, N. C. (2002). Exercise: A behavioral intervention to enhance brain health and plasticity. Trends in Neurosciences, 25(6), 295-301. [DOI:10.1016/S01662236(02)02143-4]

Dayan, E., \& Cohen, L. G. (2011). Neuroplasticity subserving motor skill learning. Neuron, 72(3), 443-54. [DOI:10.1016/j neuron.2011.10.008] [PMID] [PMCID]

Della-Maggiore, V., \& McIntosh, A. R. (2005). Time course of changes in brain activity and functional connectivity associated with long-term adaptation to a rotational transformation. Journal of Neurophysiology, 93(4), 2254-62. [DOI:10.1152/ jn.00984.2004] [PMID]

Ding, Y., Li, J., Luan, X., Ding, Y. H., Lai, Q., \& Rafols, J. A., et al. (2004). Exercise pre-conditioning reduces brain damage in ischemic rats that may be associated with regional angiogenesis and cellular overexpression of neurotrophin. Neuroscience, 124(3), 583-91. [DOI:10.1016/j.neuroscience.2003.12.029] [PMID]

Dishman, R. K., Berthoud, H. R., Booth, F. W., Cotman, C. W., Edgerton, V. R., \& Fleshner, M. R., et al. (2006). Neurobiology of Exercise. Obesity, 14(3), 345-56. [DOI:10.1038/oby.2006.46] [PMID]

Doyon, J., \& Benali, H. (2005). Reorganization and plasticity in the adult brain during learning of motor skills. Current Opinion in Neurobiology, 15(2), 161-7. [DOI:10.1016/j.conb.2005.03.004] [PMID]

Draganski, B., \& May, A. (2008). Training-induced structural changes in the adult human brain. Behavioural Brain Research, 192(1), 137-42. [DOI:10.1016/j.bbr.2008.02.015] [PMID]

Duchesne, C., Gheysen, F., Bore, A., Albouy, G., Nadeau, A., \& Robillard, M. E., et al. (2016). Influence of aerobic exercise training on the neural correlates of motor learning in Parkinson's disease individuals. NeuroImage: Clinical, 12, 559-69. [DOI:10.1016/j.nicl.2016.09.011] [PMID] [PMCID]

Eiland, L., \& Romeo, R. D. (2013). Stress and the developing adolescent brain. Neuroscience, 249(Supplement C), 162-71. [DOI:10.1016/j.neuroscience.2012.10.048] [PMID] [PMCID]

Erickson, K. I., Raji, C. A., Lopez, O. L., Becker, J. T., Rosano, C., \& Newman, A. B., et al. (2010). Physical activity predicts 
gray matter volume in late adulthood: The cardiovascular health study(e-pub ahead of print). Neurology, 75(16), 1415-22. [DOI:10.1212/WNL.0b013e3181f88359] [PMID] [PMCID]

Erickson, K. I., Weinstein, A. M., Sutton, B. P., Prakash, R. S., Voss, M. W., \& Chaddock, L., et al. (2012). Beyond vascularization: Aerobic fitness is associated with N-acetylaspartate and working memory. Brain and Behavior, 2(1), 32-41. [DOI:10.1002/brb3.30] [PMID] [PMCID]

Ermutlu, N., Yücesir, I., Eskikurt, G., Temel, T., \& İşoğlu-Alkaç, Ü. (2015). Brain electrical activities of dancers and fast ball sports athletes are different. Cognitive Neurodynamics, 9(2), 257-63. [DOI:10.1007/s11571-014-9320-2] [PMID] [PMCID]

Flöel, A., Ruscheweyh, R., Krüger, K., Willemer, C., Winter, B., \& Völker, K., et al. (2010). Physical activity and memory functions: Are neurotrophins and cerebral gray matter volume the missing link? NeuroImage, 49(3), 2756-63. [DOI:10.1016/j.neuroimage.2009.10.043] [PMID]

Friedman, L., Kenny, J. T., Wise, A. L., Wu, D., Stuve, T. A., \& Miller, D. A., et al. (1998). Brain activation during silent word generation evaluated with functional MRI. Brain and Language, 64(2), 231-56. [DOI:10.1006/brln.1998.1953] [PMID]

Gerber, P., Schlaffke, L., Heba, S., Greenlee, M. W., Schultz, T., \& Schmidt-Wilcke, T. (2014). Juggling revisited - A voxel-based morphometry study with expert jugglers. NeuroImage, 95, 320-5. [DOI:10.1016/j.neuroimage.2014.04.023] [PMID]

Ghilardi, M.-F., Ghez, C., Dhawan, V., Moeller, J., Mentis, M., \& Nakamura, T., et al. (2000). Patterns of regional brain activation associated with different forms of motor learning. Brain Research, 871(1), 127-45. [DOI:10.1016/S0006-8993(00)02365-9]

Goble, D. J., Coxon, J. P., Van Impe, A., De Vos, J., Wenderoth, N., \& Swinnen, S. P. (2010). The neural control of bimanual movements in the elderly: Brain regions exhibiting age-related increases in activity, frequency-induced neural modulation, and task-specific compensatory recruitment. Human Brain Mapping, 31(8), 1281-95. [DOI:10.1002/hbm.20943] [PMID] [PMCID]

Gonzales, M. M., Tarumi, T., Kaur, S., Nualnim, N., Fallow, B. A., \& Pyron, M., et al. (2013). Aerobic fitness and the brain: Increased $\mathrm{N}$-Acetyl-Aspartate and choline concentrations in endurancetrained middle-aged adults. Brain Topography, 26(1), 126-34. [DOI:10.1007/s10548-012-0248-8] [PMID] [PMCID]

Goodale, M. A., \& Milner, A. D. (1992). Separate visual pathways for perception and action. Trends in Neurosciences, 15(1), 20-5. [DOI:10.1016/0166-2236(92)90344-8]

Greicius, M. D., Krasnow, B., Reiss, A. L., \& Menon, V. (2003). Functional connectivity in the resting brain: A network analysis of the default mode hypothesis. Proceedings of the National Academy of Sciences of the United States of America, 100(1), 253-8. [DOI:10.1073/pnas.0135058100] [PMID] [PMCID]

Gross, C. G. (2000). Neurogenesis in the adult brain: Death of a dogma. Nature Reviews Neuroscience, 1(1), 67-73. [DOI:10.1038/35036235] [PMID]

Hamzei, F., Glauche, V., Schwarzwald, R., \& May, A. (2012). Dynamic gray matter changes within cortex and striatum after short motor skill training are associated with their increased functional interaction. NeuroImage, 59(4), 3364-72. [DOI:10.1016/j.neuroimage.2011.10.089] [PMID]
Hellhammer, D. H., Wüst, S., \& Kudielka, B. M. (2009). Salivary cortisol as a biomarker in stress research. Psychoneuroendocrinology, 34(2), 163-71. [DOI:10.1016/j.psyneuen.2008.10.026] [PMID]

Heo, Y. M., Shin, M.S., Kim, S. H., Kim, T. W., Baek, S. B., \& Baek, S. S. (2014). Treadmill exercise ameliorates disturbance of spatial learning ability in scopolamine-induced amnesia rats. Journal of Exercise Rehabilitation, 10(3), 155-61. [DOI:10.12965/ jer.140110] [PMCID]

Herrera, J. J., Fedynska, S., Ghasem, P. R., Wieman, T., Clark, P. J., \& Gray, N., et al. (2016). Neurochemical and behavioral indices of exercise reward are independent of exercise controllability. The European Journal of Neuroscience, 43(9), 1190-202. [DOI:10.1111/ejn.13193] [PMID] [PMCID]

Hillman, C. H., Erickson, K. I., \& Kramer, A. F. (2008). Be smart, exercise your heart: Exercise effects on brain and cognition. Nature Reviews Neuroscience, 9(1), 58-65. [DOI:10.1038/ nrn2298] [PMID]

Jacini, W. F. S., Cannonieri, G. C., Fernandes, P. T., Bonilha, L., Cendes, F., \& Li, L. M. (2009). Can exercise shape your brain? Cortical differences associated with judo practice. Journal of Science and Medicine in Sport, 12(6), 688-90. [DOI:10.1016/j. jsams.2008.11.004] [PMID]

Keihani, A., Ekhtiari, H., Batouli, S. A. H., Shahbabaie, A., Sadighi, N., \& Mirmohammad, M., et al. (2017). Lower gray matter density in the anterior cingulate cortex and putamen can be traceable in chronic heroin dependents after over three months of successful abstinence. Iranian Journal of Radiology, 14(3), e41858. [DOI:10.5812/iranjradiol.41858]

Kim, H. Y. (2015). Statistical notes for clinical researchers: Effect size. Restorative Dentistry \& Endodontics, 40(4), 328-31. [DOI:10.5395/rde.2015.40.4.328] [PMID] [PMCID]

Kim, H. Y. (2016). Statistical notes for clinical researchers: Sample size calculation 1. comparison of two independent sample means. Restorative Dentistry \& Endodontics, 41(1), 74-8. [DOI:10.5395/ rde.2016.41.1.74] [PMID] [PMCID]

Kleim, J. A., Barbay, S., Cooper, N. R., Hogg, T. M., Reidel, C. N., \& Remple, M. S., et al. (2002). Motor Learning-dependent synaptogenesis is localized to functionally reorganized motor cortex. Neurobiology of Learning and Memory, 77(1), 63-77. [DOI:10.1006/ nlme.2000.4004] [PMID]

Kobilo, T., Liu, Q. R., Gandhi, K., Mughal, M., Shaham, Y., \& van Praag, H. (2011). Running is the neurogenic and neurotrophic stimulus in environmental enrichment. Learning $\mathcal{E}$ Memory, 18(9), 605-9. [DOI:10.1101/lm.2283011] [PMID] [PMCID]

Kramer, A. F., Hahn, S., Cohen, N. J., Banich, M. T., McAuley, E., \& Harrison, C. R., et al. (1999). Ageing, fitness and neurocognitive function. Nature, 400(6743), 418-9. [DOI:10.1038/22682] [PMID]

Kuipers, H., Keizer, H. A., De Vries, T., Van Rijthoven, P., \& Wijts, M. (1988). Comparison of heart rate as a non-invasive determinant of anaerobic threshold with the lactate threshold when cycling. European Journal of Applied Physiology and Occupational Physiology, 58(3), 303-6. [DOI:10.1007/BF00417267] [PMID]

Landi, S. M., Baguear, F., \& Della-Maggiore, V. (2011). One week of motor adaptation induces structural changes in primary motor cortex that predict long-term memory one year later. The Journal of Neuroscience: The Official Journal of the Society for Neuroscience, 31(33), 11808-13. [DOI:10.1523/JNEUROSCI.2253-11.2011] [PMID] [PMCID] 
Lee, D. W., Miyasato, L. E., \& Clayton, N. S. (1998). Neurobiological bases of spatial learning in the natural environment: Neurogenesis and growth in the avian and mammalian hippocampus. Neuroreport, 9(7), 15-27. [DOI:10.1097/00001756-199805110-00076]

Lerch, J. P., Yiu, A. P., Martinez-Canabal, A., Pekar, T., Bohbot, V. D., \& Frankland, P. W., et al. (2011). Maze training in mice induces MRI-detectable brain shape changes specific to the type of learning. NeuroImage, 54(3), 2086-95. [DOI:10.1016/j.neuroimage.2010.09.086] [PMID]

Lerner, J., \& Keltner, D. (2001). Fear, anger, and risk. Journal of Personality and Social Psychology, 81(1), 146-59. [DOI:10.1037/00223514.81.1.146] [PMID]

Li, G., Ma, X., Bian, H., Sun, X., Zhai, N., \& Yao, M., et al. (2015). A pilot fMRI study of the effect of stressful factors on the onset of depression in female patients. Brain Imaging and Behavior, 10(1), 195-202. [DOI:10.1007/s11682-015-9382-8] [PMID] [PMCID]

Liégeois, F., Connelly, A., Cross, J. H., Boyd, S. G., Gadian, D. G., \& Vargha-Khadem, F., et al. (2004). Language reorganization in children with early-onset lesions of the left hemisphere: An fMRI study. Brain, 127(6), 1229-36. [DOI:10.1093/brain/awh159] [PMID]

Liu-Ambrose, T., Nagamatsu, L. S., Voss, M. W., Khan, K. M., \& Handy, T. C. (2012). Resistance training and functional plasticity of the aging brain: A 12-month randomized controlled trial. Neurobiology of Aging, 33(8), 1690-8. [DOI:10.1016/j.neurobiolaging.2011.05.010] [PMID]

Lövdén, M., Bäckman, L., Lindenberger, U., Schaefer, S., \& Schmiedek, F. (2010). A theoretical framework for the study of adult cognitive plasticity. Psychological Bulletin, 136(4), 659-76. [DOI:10.1037/a0020080] [PMID]

Lutz, J., Herwig, U., Opialla, S., Hittmeyer, A., Jäncke, L., \& Rufer, M., et al. (2014). Mindfulness and emotion regulation-an fMRI study. Social Cognitive and Affective Neuroscience, 9(6), 776-85. [DOI:10.1093/scan/nst043] [PMID] [PMCID]

Maguire, E. A., Gadian, D. G., Johnsrude, I. S., Good, C. D., Ashburner, J., \& Frackowiak, R. S. J., et al. (2000). Navigation-related structural change in the hippocampi of taxi drivers. Proceedings of the National Academy of Sciences, 97(8), 4398-403. [DOI:10.1073/ pnas.070039597] [PMID] [PMCID]

Maguire, E. A., Spiers, H. J., Good, C. D., Hartley, T., Frackowiak, R. S. J., \& Burgess, N. (2003). Navigation expertise and the human hippocampus: A structural brain imaging analysis. Hippocampus, 13(2), 250-9. [DOI:10.1002/hipo.10087] [PMID]

Mårtensson, J., Eriksson, J., Bodammer, N. C., Lindgren, M., Johansson, M., \& Nyberg, L., et al. (2012). Growth of language-related brain areas after foreign language learning. Neurolmage, 63(1), 240-4. [DOI:10.1016/j.neuroimage.2012.06.043] [PMID]

Mazziotta, J. C., Woods, R., Iacoboni, M., Sicotte, N., Yaden, K., \& Tran, M., et al. (2009). The myth of the normal, average human brain-The ICBM experience: (1) Subject screening and eligibility. NeuroImage, 44(3), 914-22. [DOI:10.1016/j.neuroimage.2008.07.062] [PMID] [PMCID]

McEwen, B. S., Nasca, C., \& Gray, J. D. (2015). Stress effects on neuronal structure: Hippocampus, amygdala, and prefrontal cortex. Neuropsychopharmacology, 41(1), 3-23. [DOI:10.1038/ npp.2015.171] [PMID] [PMCID]
Merriam, E. P., \& Colby, C. L. (2005). Active vision in parietal and extrastriate cortex. The Neuroscientist, 11(5), 484-93. [DOI:10.1177/1073858405276871] [PMID]

Mobbs, D., Marchant, J. L., Hassabis, D., Seymour, B., Tan, G., \& Gray, M., et al. (2009). From threat to fear: The neural organization of defensive fear systems in humans. The Journal of Neuroscience: The Official Journal of the Society for Neuroscience, 29(39), 12236-43. [DOI:10.1523/JNEUROSCI.2378-09.2009] [PMID] [PMCID]

Molenberghs, P., Ogilvie, C., Louis, W. R., Decety, J., Bagnall, J., \& Bain, P. G. (2015). The neural correlates of justified and unjustified killing: An fMRI study. Social Cognitive and Affective Neuroscience, 10(10), 1397-404. [DOI:10.1093/scan/nsv027] [PMID] [PMCID]

Mueller, K., Möller, H. E., Horstmann, A., Busse, F., Lepsien, J., \& Blüher, M., et al. (2015). Physical exercise in overweight to obese individuals induces metabolic- and neurotrophic-related structural brain plasticity. Frontiers in Human Neuroscience, 9, 372. [DOI:10.3389/fnhum.2015.00372] [PMID] [PMCID]

Niemann, C., Godde, B., Staudinger, U. M., \& Voelcker-Rehage, C. (2014). Exercise-induced changes in basal ganglia volume and cognition in older adults. Neuroscience, 281, 147-63. [DOI:10.1016/j.neuroscience.2014.09.033] [PMID]

Niemann, C., Godde, B., \& Voelcker-Rehage, C. (2016). Senior dance experience, cognitive performance, and brain volume in older women. Neural Plasticity, 2016, 9837321. [DOI:10.1155/2016/9837321] [PMID] [PMCID]

O'Hare, A. J., Dien, J., Waterson, L. D., \& Savage, C. R. (2008). Activation of the posterior cingulate by semantic priming: A co-registered ERP/fMRI study. Brain Research, 1189, 97-114. [DOI:10.1016/j.brainres.2007.10.095] [PMID]

Oden, K. B., Lohani, M., McCoy, M., Crutchfield, J., \& Rivers, S. (2015). Embedding emotional intelligence into military training contexts. Procedia Manufacturing, 3(Supplement C), 4052-9. [DOI:10.1016/j.promfg.2015.07.976]

Padival, M. A., Blume, S. R., Vantrease, J. E., \& Rosenkranz, J. A. (2015). Qualitatively different effect of repeated stress during adolescence on principal neuron morphology across lateral and basal nuclei of the rat amygdala. Neuroscience, 291(Supplement C), 128-45. [DOI:10.1016/j.neuroscience.2015.02.012] [PMID] [PMCID]

Pajonk, F. G., Wobrock, T., Gruber, O., Scherk, H., Berner, D., \& Kaizl, I., et al. (2010). Hippocampal plasticity in response to exercise in schizophrenia. Archives of General Psychiatry, 67(2), 133-43. [DOI:10.1001/archgenpsychiatry.2009.193] [PMID]

Palmer, T. D., Willhoite, A. R., \& Gage, F. H. (2000). Vascular niche for adult hippocampal neurogenesis. The Journal of Comparative Neurology, 425(4), 479-94. [DOI:10.1002/10969861(20001002)425:43.0.CO;2-3]

Paulus, M. P., Simmons, A. N., Fitzpatrick, S. N., Potterat, E. G., Van Orden, K. F., \& Bauman, J., et al. (2010). Differential brain activation to angry faces by elite warfighters: Neural processing evidence for enhanced threat detection. PloS One, 5(4), e10096. [DOI:10.1371/journal.pone.0010096] [PMID] [PMCID]

Pereira, A. C., Huddleston, D. E., Brickman, A. M., Sosunov, A. A., Hen, R., \& McKhann, G. M., et al. (2007). An in vivo correlate of exercise-induced neurogenesis in the adult dentate gyrus. Proceedings of the National Academy of Sciences of the United States 
of America, 104(13), 5638-43. [DOI:10.1073/pnas.0611721104] [PMID] [PMCID]

Perini, R., Bortoletto, M., Capogrosso, M., Fertonani, A., \& Miniussi, C. (2016). Acute effects of aerobic exercise promote learning. Scientific Reports, 6, 25440. [DOI:10.1038/srep25440] [PMID] [PMCID]

Phelps, E. A. (2004). Human emotion and memory: Interactions of the amygdala and hippocampal complex. Current Opinion in Neurobiology, 14(2), 198-202. [DOI:10.1016/j.conb.2004.03.015] [PMID]

Raine, A., \& Yang, Y. (2006). Neural foundations to moral reasoning and antisocial behavior. Social Cognitive and Affective Neuroscience, 1(3), 203-13. [DOI:10.1093/scan/ns1033] [PMID] [PMCID]

Raio, C. M., \& Phelps, E. A. (2015). The influence of acute stress on the regulation of conditioned fear. Neurobiology of Stress, 1 134-46. [DOI:10.1016/j.ynstr.2014.11.004] [PMID] [PMCID]

Raz, N., Gunning-Dixon, F., Head, D., Rodrigue, K. M., Williamson, A., \& Acker, J. D. (2004). Aging, sexual dimorphism, and hemispheric asymmetry of the cerebral cortex: Replicability of regional differences in volume. Neurobiology of Aging, 25(3), 377-96. [DOI:10.1016/S0197-4580(03)00118-0]

Rodman, H. R., \& Albright, T. D. (1987). Coding of visual stimulus velocity in area MT of the macaque. Vision Research, 27(12), 2035-48. [DOI:10.1016/0042-6989(87)90118-0]

Rovio, S., Spulber, G., Nieminen, L. J., Niskanen, E., Winblad, B., \& Tuomilehto, J., et al. (2010). The effect of midlife physical activity on structural brain changes in the elderly. Neurobiology of $\mathrm{Ag}$ ing, 31(11), 1927-36. [DOI:10.1016/j.neurobiolaging.2008.10.007] [PMID]

Ruegg, D. G., Kakebeeke, T. H., Gabriel, J.-P., \& Bennefeld, M. (2003). Conduction velocity of nerve and muscle fiber action potentials after a space mission or a bed rest. Clinical Neurophysiology, 114(1), 86-93. [DOI:10.1016/S1388-2457(02)00329-2]

Ruscheweyh, R., Willemer, C., Krüger, K., Duning, T., Warnecke, T., \& Sommer, J., et al. (2011). Physical activity and memory functions: An interventional study. Neurobiology of Aging, 32(7), 130419. [DOI:10.1016/j.neurobiolaging.2009.08.001] [PMID]

Sachdev, P. S., Lee, T., Wen, W., Ames, D., Batouli, A. H., \& Bowden, J., et al. (2013). The contribution of twins to the study of cognitive ageing and dementia: The Older Australian Twins Study. International Review of Psychiatry, 25(6), 738-47. [DOI:10.3109/09540 261.2013.870137] [PMID]

Schlaffke, L., Lissek, S., Lenz, M., Brüne, M., Juckel, G., \& Hinrichs, T., et al. (2014). Sports and brain morphology - a voxel-based morphometry study with endurance athletes and martial artists. Neuroscience, 259, 35-42. [DOI:10.1016/j.neuroscience.2013.11.046] [PMID]

Schubotz, R. I., \& von Cramon, D. Y. (2001). Functional organization of the lateral premotor cortex: fMRI reveals different regions activated by anticipation of object properties, location and speed. Cognitive Brain Research, 11(1), 97-112. [DOI:10.1016/S09266410(00)00069-0]

Sehm, B., Taubert, M., Conde, V., Weise, D., Classen, J., \& Dukart, J., et al. (2014). Structural brain plasticity in Parkinson's disease induced by balance training. Neurobiology of Aging, 35(1), 232-9. [DOI:10.1016/j.neurobiolaging.2013.06.021] [PMID]
Snowden, M., Steinman, L., Mochan, K., Grodstein, F., Prohaska, T. R., \& Thurman, D. J., et al. (2011). Effect of exercise on cognitive performance in community-dwelling older adults: review of intervention trials and recommendations for public health practice and research. Journal of the American Geriatrics Society, 59(4), 704-16. [DOI:10.1111/j.1532-5415.2011.03323.x] [PMID]

Steinbeis, N., Engert, V., Linz, R., \& Singer, T. (2015a). The effects of stress and affiliation on social decision-making: Investigating the tend-and-befriend pattern. Psychoneuroendocrinology, 62, 138-148. [DOI:10.1016/j.psyneuen.2015.08.003] [PMID]

Steinbeis, N., Engert, V., Linz, R., \& Singer, T. (2015b). The effects of stress and affiliation on social decision-making: Investigating the tend-and-befriend pattern. Psychoneuroendocrinology, 62, 138-48. [DOI:10.1016/j.psyneuen.2015.08.003] [PMID]

Stickgold, R., Malia, A., Maguire, D., Roddenberry, D., \& O'Connor M. (2000). Replaying the game: Hypnagogic images in normals and amnesics. Science, 290(5490), 350-3. [DOI:10.1126/science.290.5490.350] [PMID]

Tang, S. W., Chu, E., Hui, T., Helmeste, D., \& Law, C. (2008). Influence of exercise on serum brain-derived neurotrophic factor concentrations in healthy human subjects. Neuroscience Letters, 431(1), 62-5. [DOI:10.1016/j.neulet.2007.11.019] [PMID]

Thomas, A. G., Dennis, A., Rawlings, N. B., Stagg, C. J., Matthews, L., \& Morris, M., et al. (2016). Multi-modal characterization of rapid anterior hippocampal volume increase associated with aerobic exercise. NeuroImage, 131, 162-70. [DOI:10.1016/j.neuroimage.2015.10.090] [PMID] [PMCID]

Tran, V. (2013). Positive Affect Negative Affect Scale (PANAS) BT - Encyclopedia of Behavioral Medicine. In M. D. Gellman \& J. R. Turner (Eds.), Chapter 3, (pp. 1508-1509). New York, NY: Springer New York. [DOI:10.1007/978-1-4419-1005-9_978]

Trautmann, S. A., Fehr, T., \& Herrmann, M. (2009). Emotions in motion: Dynamic compared to static facial expressions of disgust and happiness reveal more widespread emotion-specific activations. Brain Research, 1284(Supplement C), 100-15. [DOI:10.1016/j. brainres.2009.05.075] [PMID]

van Praag, H. (2009). Exercise and the brain: Something to chew on. Trends in Neurosciences, 32(5), 283-90. [DOI:10.1016/j. tins.2008.12.007] [PMID] [PMCID]

van Praag, H., Kempermann, G., \& Gage, F. H. (2000). Neural consequences of enviromental enrichment. Nature Reviews Neuroscience, 1(3), 191-8. [DOI:10.1038/35044558] [PMID]

van Wingen, G. A., Geuze, E., Caan, M. W. A., Kozicz, T., Olabarriaga, S. D., \& Denys, D., et al. (2012). Persistent and reversible consequences of combat stress on the mesofrontal circuit and cognition. Proceedings of the National Academy of Sciences, 109(38) 15508-13. [DOI:10.1073/ pnas.1206330109] [PMID] [PMCID]

Voelcker-Rehage, C., Godde, B., \& Staudinger, U. M. (2011). Cardiovascular and coordination training differentially improve cognitive performance and neural processing in older adults. Frontiers in Human Neuroscience, 5, 26. [DOI:10.3389/fnhum.2011.00026] [PMID] [PMCID]

Voss, M. W., Vivar, C., Kramer, A. F., \& van Praag, H. (2013). Bridging animal and human models of exercise-induced brain plasticity. Trends in Cognitive Sciences, 17(10), 525-44. [DOI:10.1016/j. tics.2013.08.001] [PMID] [PMCID]

Wei, G., Zhang, Y., Jiang, T., \& Luo, J. (2011). Increased Cortical Thickness in Sports Experts: A Comparison of Diving Players 
with the Controls. PloS One, 6(2), e17112. [DOI:10.1371/journal. pone.0017112] [PMID] [PMCID]

Weinstein, A. M., Voss, M. W., Prakash, R. S., Chaddock, L., Szabo, A., \& White, S. M., et al. (2012). The association between aerobic fitness and executive function is mediated by prefrontal cortex volume. Brain, Behavior, and Immunity, 26(5), 811-9. [DOI:10.1016/j.bbi.2011.11.008] [PMID] [PMCID]

Yau, S., Gil-Mohapel, J., Christie, B. R., \& So, K. (2014). Physical exercise-induced adult neurogenesis: A good strategy to prevent cognitive decline in neurodegenerative diseases? BioMed Research International, 2014, 403120. [DOI:10.1155/2014/403120] [PMID] [PMCID] 
This Page Intentionally Left Blank 